\title{
Improved Deep Convolution Neural Networks Classification Amygdala of Image Mining Technique using ASD Accuracy
}

\author{
R.Lalitha, J. Jebamalar Tamilselvi
}

\begin{abstract}
Image mining is as of now a developing dynamic research center in computer science. Generally clear inside the initial couple of long periods of life. One of as of late most seriously contemplated related with fMRI a differing gathering of medicinal conditions. In mentally unbalanced kids this actuation is anomalous of their moms mining lessened when Images of outsiders indicated. Functional magnetic resonance imaging to distinguish Tuberous Sclerosis bigger right amygdala volume has been related with more extreme social and open hindrances in mentally unbalanced two year olds. This work, semantic division as relating exhibited bigger amygdalae structures among kids with profound convolutions neural systems. Conduct articulations of the extreme introvert tend coming about basic and utilitarian irregularities in the cerebrum. Promising Tools Neuro Imaging Analysis Kit (NIAK) for UCI Dataset Autism Screening Adult(ASA) division sushisen algorithm utilizing essentially includes decrease systems less amygdala enactment amid the assignment enhance fMRI check and the Issue arrangement $C N N$ rise 94.88 percent accuracies of a rate.
\end{abstract}

Keywords : Autism Spectrum Disorder; CNN; Image Mining; Functional Magnetic Resonance Imaging.

\section{INTRODUCTION}

Today, a standout amongst the most encouraging strategies for creating valuable data for cerebrum tissue portrayal is Functional Magnetic resonance imaging (FMRI). So as to remove the symptomatic data of various parameters reflected in X-ray, images investigation strategies have been utilized. Cerebrum tumor portrayal is a procedure that requires a confounded appraisal of the different activity fMRI includes(Vrtička et al., 2011) and is regularly performed by experienced radiologists. A specialist radiologist plays out this undertaking with a noteworthy level of exactness and precision, in spite of the characteristically emotional nature of a large number of the choices related with this procedure ASQ is short of called ASA. The push to convey more powerful AD treatment amygdale (Nuss, P et al., 2015), clinicians are consistently looking for more noteworthy precision in the obsessive portrayal of cerebrum tissues from imaging investigations Recent epidemiological

Revised Manuscript Received on July 22, 2019.

R.Lalitha, Research Scholar,Bharathiar University, Coimbatore, Tamil Nadu, India

Dr. J. JebamalarTamilselvi, Research Guide \& Professor,Department of CSE,Jaya Engineering College, Chennai, Tamil Nadu, India examinations have recorded an overall increment in the quantity of people related to a mental imbalance over the previous decade. While early research proposed the great extreme introverted Feature extraction BELBIC (Sangram Redkar et al., 2015) to be generally uncommon, later discoveries recommend that when seen as a range youngster at the milder end of the range a mental imbalance is significantly more common than beforehand thought (Chakrabarti et al 2005). While enhanced indicative practices and extended characterization frameworks represent a part of this expansion, a few scientists presently trusted that mining to be recognized ecological components may have risen in ongoing decades that place babies and youngsters at the expanded hazard for creating the extreme introverted (Ozonoff et al., 2003).Despite the reason more probable the causes of this expanded rate of extreme Autism Spectrum Disorder (ASD), there is no contention that the present teachers will probably recognize and be requested to serve understudies with a mental imbalance than in years past.

A. Review of literature

What's more, another analysis of social correspondence issue Image mining was made for kids who don't fit the criteria of ASD in light of the fact that they needed monotonous practices, mining at the same time experienced verbal and nonverbal correspondence shortfalls that adversely influenced their social connections previously the age of 3 (Mahjouri and Ruler et al., 2012; Halfon and Kuok et al., 2013).

Furthermore, preceding techniques focused over segmenting the intelligence between the three major plantain classes: $\mathrm{CNN}$ (Khalili et al., 2019) cortical mature be counted and ventricles. However, characteristics regarding other skill classes, certain as much cerebellum (CB) then brain stem (BS), are important in accordance with apprehend then augur wholesome yet aberrant intelligence improvement of preterm infants on comparable gestational majority as like fetuses (Bouyssi-Kobar et al., 2012). The cerebellum is in particular concerning medical pastime as it is one regarding the fastest growing brain regions all through the closing trimester on being pregnant(Dobbing et al., 1973).

An appraisal by Huerta and associates thought about the distinctive rates of affectability and specificity of DSM-IV versus DSM-V in diagnosing ASD, and announced that $91 \%$ of patients determined to have

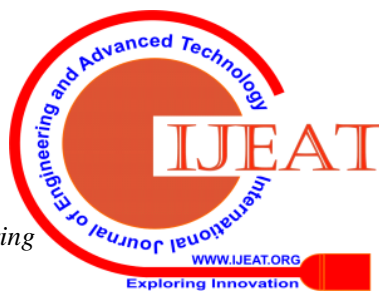


ASD utilizing DSM-IV held this determination when utilizing DSM-V (Huerta et al,.2012).

\section{ASD CLASSIFICATION AMYGDALA}

\section{A. ASD Image Solving}

The point of the present appraisal was to configuration, executes and assesses an example acknowledgment framework which by breaking down routinely taken T1 post-differentiate fMRI (Vrtička et al., 2011) would enhance cerebrum tumor grouping precision. Utilizing a two-level progressive choice tree, refinement amongst metastatic and essential cerebra ASD and amongst gliomas and meningiomas were performed at the first and second level of the choice tree separately.

\section{B. ASD Problem}

In many investigations, the real dataset, the normal patients are taken from the same land zone, which increment the likelihood for them to have a place similar predecessor. In mental malady the control tests are being taken from the real data sets of the patient. This will expand the likeness in SNP Cluster between the case fMRI and the control in accuracy results.

\section{Datasets}

In this work the new dataset UCI Dataset Autism Screening Adult(ASA) in the predictive task developed 24-12-2017 identified with a mental imbalance screening of grown-ups that contained male and female 240 People data set bring to light to be used for promote investigation particularly indeterminism powerful extremely introverted qualities and enhancing the arrangement of ASD 704 Instances NIAK alleles.

\section{Flow chart}

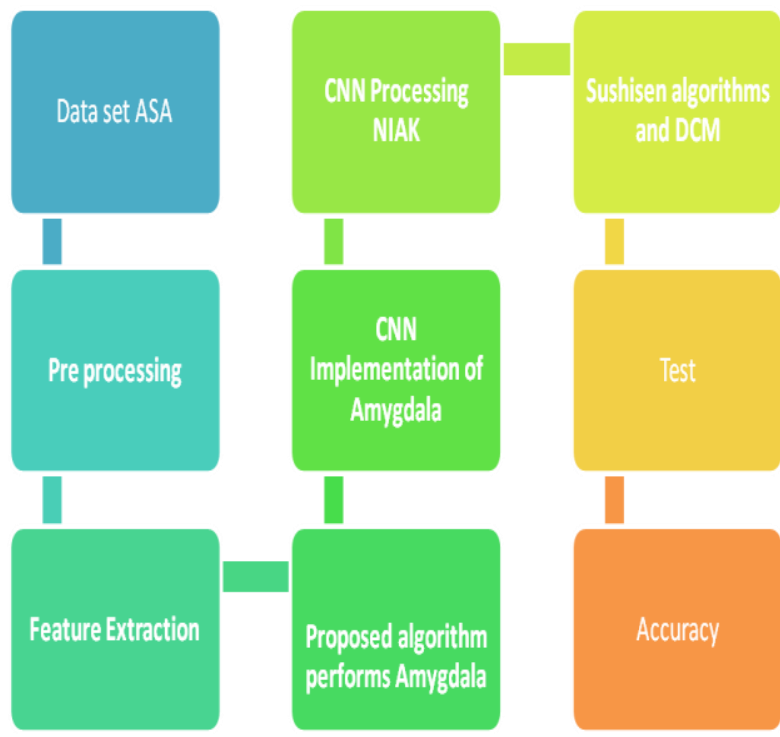

Fig 1: Convolution Neural Networks using Autism Spectrum Disorder Classification Amygdala

\section{FMRI CLASSIFICATION AMYGDALAE}

The amygdalae is in charge of figuring out what recollections are put away in your cerebrum. Amygdale in enthusiastic control and dread control. Battle responses manager of the cerebrum, judging each new sensation to be a risk faculty on alarm everything that we sense has just been separated through our enthusiastic brain amygdale images.

\section{Pre processing}

The first before the dataset has achieved any piece of the cerebral cortex that enables us to process and think rationally remember a past risk the same extreme feelings; we may not know about the memory that has been activated. It is building up another Element Choice strategy called Pertinent Component Choice step-by-step analysis Image preprocessing and Division of amygdale particular neuron sets. The undertaking of images preprocessing is ASD to improve the images division isolates the images into non-covering and it will isolate the items from returns on initial arrangement all dataset investment will be designated for bring to lights Feature extraction BELBIC . Median Filtering using Gray durability stability Level dynamic causal modelling (DCM) (Friston et al., 2003) because of the directions $0^{\circ}, 45^{\circ}, 90^{\circ}$, and $135^{\circ}$ with the distances conceit segmentation divides the image of non-overlapping longevity regions, yet it intention resolve the objects beside the longevity background. The demographics of the fifty two sufferers included among it lesson are detailed of fig 2 . Briefly, the precedence on patients had been male $(n=29$, $67 \%$ ), or the median majority concerning patients at the age concerning treatment was fifty four years (range 7-80). Most patients had norm III-IV glioma $(\mathrm{n}=36,88 \%)$. The almost frequent gland areas had been frontal lobe $(\mathrm{n}=11,25 \%)$ and civil lobe $(\mathrm{n}=10,41 \%)$. All patients were handled including intensity modulated RT, yet near patients $(n=52,88 \%)$ received 30 fractions of partial-brain $\mathrm{RT}$. The vast majority concerning sufferers obtained chemotherapy during the learning period $(n=51,98 \%)$. Fifteen patients $(39 \%)$ had a most important seizure during the study period and ten (29\%) sufferers received bevacizumab.

\section{Feature Extraction}

An aggregate number of 120 left and right amydala T1 weighted (Seibert et al., 2017) gadolinium-upgraded fMRI pictures were gotten from the Hellenic amygdalae Healing facility with confirmed intracranial tumors, utilizing a fMRI Unit 21 metastasis, 19 LEFT BELBIC 27 RIGHT BELBIC. Utilizing these Images, the radiologist indicated Areas of Intrigue. From every amygdale, a progression of 36 brings to light were removed 4 bring to light from the return for money invested histogram, 21 from the co-event networks, and 10 from the run-length lattices. To lessen brings to lights dimensionality, the non-parametric $\mathrm{R}$ software test was utilized bring to lights of high unfair capacity $(\mathrm{p}<0.094)$, were chosen to nourish the grouping plan.

\section{CNN Processing NIAK}

As to last two arrangements it is imperative to recognize that as scientists have come to see more about them and their separate etiologies their association with a mental imbalance has turned out to be less clear. So nearly connected with a mental imbalance later on and will be viewed as particular neurodegenerative issue. The 
LEFT BELBIC (Brain Emotional Learning Grade Intelligent Controller) arrangement calculation expanded the general precision in effectively describing essential and metastatic cerebrum tumors.

This is imperative, since the accuracy of such a choice might be vital in persistent administration, metastatic tumors require particular treatment conventions, for example, radiation treatment and chemotherapy, while essential tumors may likewise require careful intercession. The explanation for this exactness addition might be credited to the expanded class detachability that the BELBIC strategy gives, particularly when non-direct terms are presented in the classifier's discriminant work.

This characterization RIGHT BELGIC is saved for people who encounter trouble in no less than two of the three Mentally unbalanced Confusion side effect bunches, mining who don't meet the total symptomatic criteria for some other ASD. As indicated by (Filipek et al. 1999), Amygdala is certifiably not a particular clinical element. Be that as it may, people with this analysis are ordinarily seen as being milder this reality, understudies with images the meantime recognize that this analytic image at times utilized when a diagnostician is essentially hesitant to utilize the Extremely introverted neuropsychological social measure when nonverbal Asperser's Syndrome(AS) was controlled improved performed accuracy.

\section{Hippocampus Processing fMRI :}

Complementary social communication ability. The left Glama of stereotyped conduct, premiums and effort. For the most part clear inside the initial couple of long stretches of life. Frequently connected with fMRI and additionally a various gathering of restorative conditions the three symptomatic areas of Unavoidable Formative Issue. Recognize 2 noteworthy distinctive factors between mentally unbalanced Turmoil and Asperser's concern. Normally (Karunamuni et al,. 2016) T1 mental conditions and three regularly $\mathrm{T} 3$ general medicinal conditions. Distinguish the key prognostic marker for A mental imbalance ASD images based three successful medications for Extreme introverted. Depict the essential learning challenges Manic-depression Amygdala involved of creating memories of impassioned events Confirmed by means of fMRI snap shots in Bipolar disorder (BD) with inescapable formative postponements. Extremely introverted kids were verifiably accepted to be schizophrenic.

\section{CNN Implementation of Amygdala}

We have been upset by congruity different scatters, the wide scope of disorder articulation, changes in disorder articulation w/age training sets $80 \%$, high recurrence of mentally unbalanced like side effects in those w/fMRI, and the relative uncommonness of this disorder. In most cases there is no time of unequivocally typical advancement test sets $20 \%$ of report ordinary improvement for initial 1-2 yrs of life.

The most essential social Amygdale cerebrum framework. In mirror framework may mimic watched activities and along these lines add to our Hypothesis of Mind aptitudes. fMRI (Bamford et al., 2015; Gross \& Levenson, 1993; Gross, 1998) thinks analysis about have currently shown diminishing action $F(z, u, \theta)$ in the second rate frontal gyrus $\frac{\partial x}{\partial t}=(A+u B) x+C u$ in people with the extreme

This progression is to discover a list of capabilities of the therapeutic images that can precisely recognize benevolent/dangerous. The element space could be huge and complex, so removing and choosing the best bring to light is essential. Decision Emotionally supportive network. Based on the chose bring to light, the suspicious districts will be named typical favorable by different grouping strategies

A $\operatorname{dim}$ Level fig. 2 ascertained for the headings of $0^{\mathrm{o}-0}$, $45^{\mathrm{o}-1}, 90^{\mathrm{o}-2}$, and $135^{\mathrm{o}-3}$ and $155^{\mathrm{o}}-4$ for the separations.

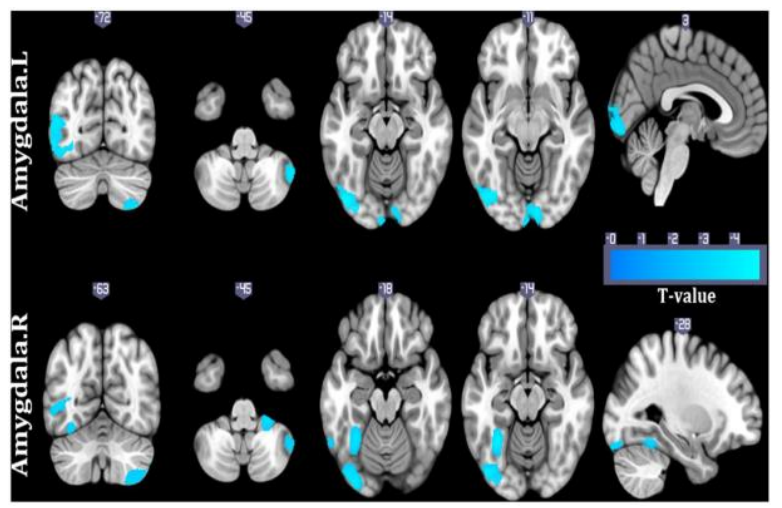

Fig 2: Filtering is a technique because of enhancing and improving an image RGB Components Processing

\section{Proposed algorithm performs Amygdalae}

Supervised channel based Component Determination calculation. Performs discretization process for the ceaseless estimations of the bring to light extraction and chooses most important bring to lights considers one element at any given moment. Sorts the consistent estimations of individual element attempts to discover interim split focuses that has a solid larger part of one specific class.

Definition 1: Class $\frac{d z}{d t}$ is the vital catchphrase of a therapeutic images determination given by radiologist $F(z, u, \theta)$.

$$
\frac{d z}{d t}=F(z, u, \theta)
$$

Definition 2: Split ( \&\&) Focus are the cutoff points of an interim of qualities.

$$
\left[\begin{array}{l}
\mathbb{W} \\
\mathbb{W}
\end{array}\right]=\left(\left[\begin{array}{ll}
A_{11} & A_{12} \\
A_{21} & A_{22}
\end{array}\right]+\left[\begin{array}{ll}
0 & B^{2}{ }_{12} \\
0 & 0
\end{array}\right] U_{2}\right)\left[\begin{array}{l}
x_{1} \\
x_{2}
\end{array}\right]+\left[\begin{array}{ll}
C_{11} & 0 \\
0 & C_{22}
\end{array}\right]\left[\begin{array}{l}
U_{1} \\
U_{2}
\end{array}\right]
$$

Definition 3: Most Successive Class $\mathrm{f}_{\mathrm{B}}(\mathrm{x}, \mathrm{u})$ is the larger part class in a specific interim $\left(\mathrm{S}_{\mathrm{j}} \mathrm{U}_{\mathrm{j}} \mathrm{B}^{\mathrm{j}} \mathrm{x}\right)$.

$$
\mathbf{f}_{B}(x, u)=\left(A+S_{j} U_{j} B^{j}\right) x+C_{i}
$$

Definition 4: A case Ii has a place with the interim $\left(\mathrm{X}_{1}\right)$, if

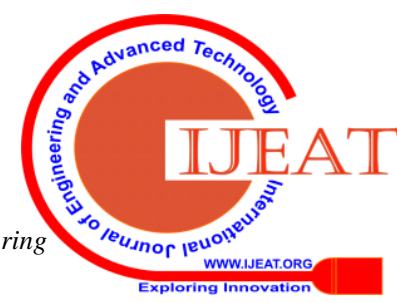


its esteem $\left(\mathrm{C}_{11} \mathrm{U}_{1}\right)$ is between two progressive split focuses $\left(\mathrm{A}_{11} \mathrm{X}_{1}\right)$ and $\left(\mathrm{A}_{21+} \mathrm{B}^{2}{ }_{12} \mathrm{U}_{1}(\mathrm{t})\right)$

$$
X_{1}=A_{11} X_{1}+\left(A_{21+} B^{2}{ }_{12} U_{1}(t)\right) X+C_{11} U_{1}
$$

\section{Two information parameters:}

RIGHT BELBIC: The base number of events of the most incessant class permitted in an interim

$$
\begin{aligned}
A & =\frac{\partial F}{\partial z}=\frac{\partial \mathbb{\&}}{\partial z} \\
B^{j} & =\frac{\partial^{2} F}{\partial z \partial u_{j}}=\frac{\partial}{\partial u_{j}} \frac{\partial \mathbb{E}}{\partial z} \\
C & =\frac{\partial F}{\partial u}=\frac{\partial \mathbb{\&}}{\partial u}
\end{aligned}
$$

LEFT BELBIC: The base inhabitance of the most incessant class in an interim

$$
\frac{d z}{d t}=\left(A+\sum_{i=1}^{m} u_{i} B^{(i)}+\sum_{j=1}^{n} z_{j} D^{(j)}\right) z+C u
$$

Condition 1: Produce split point TS if the class mark of the present case $A, X 11 \geq 1$ is not quite the same as the class name of the past occasion

$$
\mathbf{X}_{1}=\mathbf{A}_{11} \mathbf{X}_{1}+\mathbf{A}_{21} \mathbf{X}_{2}+\mathbf{C}_{11} \mathbf{U}_{1}
$$

Condition 2: The quantity of events of the most continuous class in the interim $\mathrm{Qk} \quad \mathbf{X}_{2}$ must be equivalent \pm more noteworthy than the min values.

$$
X_{2}=A_{22} X_{2}+A_{12} X_{1}+C_{22} U_{2}
$$

Condition 3: The split point $\mathrm{U} 1+\mathrm{U} 2$ of two progressive interims is expelled if the lion's share classes of the two interims are same and the quantity of events of larger part class in the interim $\mathrm{Qk} /$ number of events of dominant part class in the interim $\mathrm{X}$.

$$
\begin{aligned}
& y=h(u, \theta)+e \\
& {\left[\begin{array}{l}
\mathbb{d} \\
\&
\end{array}\right]=\left[\begin{array}{ll}
A_{11} & A_{12} \\
A_{21} & A_{22}
\end{array}\right]\left[\begin{array}{l}
x_{1} \\
x_{2}
\end{array}\right]+\left[\begin{array}{ll}
C_{11} & 0 \\
0 & C_{22}
\end{array}\right]\left[\begin{array}{l}
U_{1} \\
U_{2}
\end{array}\right]} \\
& {\left[\begin{array}{l}
\& \\
\& \\
\&
\end{array}\right]=s\left[\begin{array}{cc}
-1 & 0 \\
a_{21} & -1
\end{array}\right]\left[\begin{array}{l}
z_{1} \\
z_{2}
\end{array}\right]+\left[\begin{array}{l}
c \\
0
\end{array}\right] u_{1} \quad a_{21}>0} \\
& {\left[\begin{array}{l}
\& \\
\& \\
\&
\end{array}\right]=s\left[\begin{array}{cc}
-1 & 0 \\
a_{21} & -1
\end{array}\right]\left[\begin{array}{l}
z_{1} \\
z_{2}
\end{array}\right]+u_{2}\left[\begin{array}{cc}
0 & 0 \\
b_{21}^{2} & 0
\end{array}\right]\left[\begin{array}{l}
z_{1} \\
z_{2}
\end{array}\right]+\left[\begin{array}{l}
c \\
0
\end{array}\right] u_{1} \quad b_{21}^{2}>0} \\
& A=\left[\begin{array}{ccc}
A_{11} & \Lambda & A_{1 N} \\
\mathrm{M} & \mathrm{O} & \mathrm{M} \\
A_{N 1} & \mathrm{~K} & A_{N N}
\end{array}\right] x(t)=\left[\begin{array}{c}
x_{1} \\
\mathrm{M} \\
x_{N}
\end{array}\right]
\end{aligned}
$$

$$
\begin{gathered}
\frac{\partial x}{\partial t}=\left(A B^{u}\right) x+C u \\
A=\left[\begin{array}{ccccc}
-e^{A_{11}^{E E}} & -e^{A_{11}^{E I}} & \Lambda & e^{A_{1 N}} & 0 \\
e^{A_{11}^{E}} & -e^{A_{11}^{I I}} & & 0 & 0 \\
\mathrm{M} & & \mathrm{O} & & \mathrm{M} \\
e^{A_{N 1}} & 0 & & -e^{A_{N N}^{E E}} & -e^{A_{N N}^{E I}} \\
0 & 0 & \Lambda & e^{A_{N N}^{I E}} & -e^{A_{N N}^{I}}
\end{array}\right] x(t)=\left[\begin{array}{c}
x_{1}^{E} \\
x_{1}^{I} \\
\mathrm{M} \\
x_{N}^{E} \\
x_{N}^{I}
\end{array}\right] \\
p(\theta \mid y, m)=\frac{p(y \mid \theta, m) p(\theta \mid m)}{p(y \mid m)} \\
p(y \mid m)=\int p(y \mid \theta, m) p(\theta \mid m) d \theta=\langle\log p(y \mid \theta, m)\rangle-K L[q(\theta), p(\theta \mid m)] \\
+K L[q(\theta), p(\theta \mid y, m)] \\
\text { Finally get Results } \mathrm{p}(\mathrm{y})
\end{gathered}
$$

$\log p(y \mid m)=\operatorname{accuracy}(m)-\operatorname{complexity}(m)$

\section{A. Sushisen Algorithms}

- Input: Bring to lights UCI DataSet ASA Images class marks $\mathrm{T}$ (Three classes $\mathrm{T} 1, \mathrm{~T} 2$ and $\mathrm{T} 3$ speaks to typical, generous and dangerous separately),

- Output: include vector ASM Accuracy for chose bring to lights

1. Starts ASA

2. Utilize Condition 1 to make a vector $\mathrm{t}$ of split focuses ts $\square \mathrm{U} 1+\mathrm{U} 2$

3. end for $\mathrm{Qk} \square \mathrm{ts}+1$

4. for every ts $\mathrm{T}$ do $\mathrm{X}_{2} \square \mathrm{A}_{22} \mathrm{X}_{2}+\mathrm{A}_{12} \mathrm{X}_{1}+\mathrm{C}_{22} \mathrm{U}_{2}$

5. Expel $\mathrm{t} \mathrm{s}$ as per the condition $2 \mathrm{f}_{\mathrm{L}}(\mathrm{x}, \mathrm{u})=\mathrm{Ax}+\mathrm{Cu}$

6. Expel $\mathrm{t} \square \mathrm{s}$ union two sequential

7. interims as per the condition $\mathrm{X}_{1} \square \mathrm{A}_{11} \mathrm{X}_{1}+\left(\mathrm{A}_{21+}\right.$ $\left.\mathrm{B}^{2}{ }_{12} \mathrm{U}_{1}(\mathrm{t})\right) \mathrm{X}+\mathrm{C}_{11} \mathrm{U}_{1}$

8. end for

9. for each element $X_{1 \square} A_{11} X_{1}+A_{21} X_{2}+C_{11} U_{1}$

10. Sort v esteems $p(y \mid m)-->\int p(y \mid \theta, m) \cdot p(\theta \mid m) d \theta$

11. For every exchange I the frame T1,T2,T3

12. T1 to T3 Image sets Neuron Tools

13. Spare staying split focuses in a vector $\mathrm{fMRI}$

14. end for BPD $\square \mathrm{UCI}+\mathrm{NAIK}$

15. Organize the bring to lights in rising request in view of the quantity of split focuses

16. Select the $($ dim_reduce $*|F|)$

17. Includes a bring $\square$ lights + minimum

18. $\mathrm{CNN} \square$ number + split focuses $+\mathrm{DCM}$

19. FE $\square$ ASD-OC

20. Compose the chose

bring to
lights




\section{$p(\theta \mid y) \propto p(y \mid \theta) p(\theta) \operatorname{Sin} 0+X$}

21. Return Accuracy of CNN images $p(y \mid m)-->\int p(y \mid \theta, m) \cdot p(\theta \mid m) d \theta$ get final ASD.

\section{Discussion}

The principle motivation behind utilizing these classifiers is to quantify the execution of our proposed half-and-half component determination method $\operatorname{ASA}(C$. Allison et al 2012). The introduced classifiers are double frameworks prepared to distinguish amygdala of information to group subjects as sound or influenced. The classifiers SVM, Innocent Bayes (IB), Direct Discriminates Investigation (LDA) and KNN were utilized using mixed make new all in one algorithm sushisen algorithm in this appraisal.

Mentally unbalanced Confusion The essential side effects of Extremely introverted ASD are uniquely unusual or hindered improvement in social collaboration and correspondence and a notably limited collection of action and interests". Determination requires the nearness of at least 6 of 12 indications, with no less than two being side effects of disabled social operations, no less than one being a side effect of impeded correspondence, and no less than one being a side effect of confined collection of effort and premiums. Understudies with Extremely introverted Confusion regularly have some level of mental hindrance. Given this reality, brain images Two years kids astonishing that it has been proposed amygdala connection (Caro Lucas et al., 2004) that kids doled out this indicative grouping would likewise be qualified for a custom curriculum under Thought. AS essential indications of Childhood Autism Rating Scale (CARS) are extreme and maintained debilitation and the improvement of limited, the psychological working of people with Asperger's Issue is substantially more homogeneous. While people with Mentally unbalanced ASD are regularly psychologically weakened, the scholarly (table.1) working of people with Asperger Syndrome Diagnostic (ASD) is commonly inside ordinary points of confinement. T1,T2,T3 MR System: A fMRI Imaging provision dedicated according to research together with $27 \mathrm{mT} / \mathrm{m}$ whole-body gradients with $72 \mathrm{mT} / \mathrm{m} / \mathrm{sec}$ slew degree is reachable for the proposed DCM studies in amydalae. The rule has multi or alone audit CNN imaging capability so nicely as like the vital software program and hardware because proton spectroscopy. The system that is housed at the Center because of Functional Onco-Imaging is aged because ethnical and brute research studies Tesla: unit concerning magnetic field; earth's weight $=0.00005$. An An extremely uncommon condition. Dynamic causal model DCM like Mentally unbalanced it includes hindered advancement of social connection and correspondence; and confined, tedious, and stereotyped examples of practices, interests, and quirks. Notwithstanding, a particular example of relapse following no less than two long periods of ordinary improvement recognizes it from Mentally unbalanced Confusion. Given the serious subjective deficiencies normally connected with Rhett's Issue, it is normal Autism Spectrum Disorder-Observation for Children (ASD-DCM) will ensure these understudies as qualified for a custom curriculum help. Appraisal of analytic criteria uncovers that Amygdala is moderately unmistakable social troubles normal for Mentally unbalanced might be watched, amygdala response (Vrtička et al., 2011) they are not as unavoidable and have a tendency to be transient. Moreover, while the extreme impedance of dialect advancement that goes with Mentally unbalanced Confusion is watched, in DCM has been applied(Cao et al., 2008) such is additionally joined by serious psycho motor hindrance. Given the extreme to significant psychological deficiencies commonly connected with Rett's to ASD images low level accuracy in particular Improved as qualified for a custom curriculum help.

Table- I: Sushisen ASD With fMRI of image

\begin{tabular}{|l|l|l|l|l|l|l|l|}
\hline $\begin{array}{l}\text { Total split } \\
\text { point in } \\
\text { step1 }: \mathbf{4 4}\end{array}$ & $\begin{array}{l}\text { Split } \\
\text { point for } \\
\text { each } \\
\text { interval }\end{array}$ & $\begin{array}{l}\text { Total split } \\
\text { point in } \\
\text { step1 }: 44\end{array}$ & $\begin{array}{l}\text { Split point } \\
\text { for each } \\
\text { interval }\end{array}$ & $\begin{array}{l}\text { Total split } \\
\text { point in step2 } \\
\mathbf{2 7}\end{array}$ & $\begin{array}{l}\text { Split point } \\
\text { for each } \\
\text { interval }\end{array}$ & $\begin{array}{l}\text { Total split } \\
\text { point in step3 } \\
\text { 16 }\end{array}$ & $\begin{array}{l}\text { Split } \\
\text { point for } \\
\text { each } \\
\text { interval }\end{array}$ \\
\hline $\mathrm{sp} 1=4$ & 0.542 & $\mathrm{sp} 29=4$ & 0.903 & $\mathrm{sp} 2=5$ & 0.56 & $\mathrm{sp} 3=11$ & 0.571 \\
\hline $\mathrm{sp} 2=1$ & 0.56 & $\mathrm{sp30=2}$ & 0.914 & $\mathrm{sp} 3=6$ & 0.571 & $\mathrm{sp} 7=15$ & 0.644 \\
\hline $\mathrm{sp} 3=6$ & 0.571 & $\mathrm{sp} 31=2$ & 0.916 & $\mathrm{sp} 5=5$ & 0.623 & $\mathrm{sp} 9=5$ & 0.684 \\
\hline $\mathrm{sp} 4=1$ & 0.605 & $\mathrm{sp} 32=4$ & 0.924 & $\mathrm{sp} 7=10$ & 0.644 & $\mathrm{sp} 11=13$ & 0.705 \\
\hline $\mathrm{sp} 5=4$ & 0.623 & $\mathrm{sp} 33=6$ & 0.929 & $\mathrm{sp} 9=5$ & 0.684 & $\mathrm{sp} 14=8$ & 0.762 \\
\hline $\mathrm{sp} 6=2$ & 0.631 & $\mathrm{sp} 34=2$ & 0.935 & $\mathrm{sp} 11=13$ & 0.705 & $\mathrm{sp} 17=12$ & 0.793 \\
\hline $\mathrm{sp} 7=8$ & 0.644 & $\mathrm{sp} 35=8$ & 0.938 & $\mathrm{sp} 12=3$ & 0.72 & $\mathrm{sp} 20=8$ & 0.824 \\
\hline $\mathrm{sp} 8=1$ & 0.673 & $\mathrm{sp} 36=2$ & 0.943 & $\mathrm{sp} 14=5$ & 0.762 & $\mathrm{sp} 23=9$ & 0.852 \\
\hline $\mathrm{sp} 9=4$ & 0.684 & $\mathrm{sp} 37=6$ & 0.949 & $\mathrm{sp} 15=3$ & 0.776 & $\mathrm{sp} 28=11$ & 0.902 \\
\hline $\mathrm{sp} 10=2$ & 0.691 & $\mathrm{sp} 38=1$ & 0.952 & $\mathrm{sp} 17=9$ & 0.793 & $\mathrm{sp} 29=3$ & 0.903 \\
\hline
\end{tabular}


Improved Deep Convolution Neural Networks Classification Amygdala of Image Mining Technique using ASD Accuracy

\begin{tabular}{|l|l|l|l|l|l|l|l|}
\hline $\mathrm{sp} 11=11$ & 0.705 & $\mathrm{sp} 39=4$ & 0.958 & $\mathrm{sp} 18=4$ & 0.802 & $\mathrm{sp} 32=8$ & 0.924 \\
\hline $\mathrm{sp} 12=3$ & 0.72 & $\mathrm{sp} 40=2$ & 0.961 & $\mathrm{sp} 20=4$ & 0.824 & $\mathrm{sp} 35=16$ & 0.938 \\
\hline $\mathrm{sp} 13=1$ & 0.745 & $\mathrm{sp} 41=3$ & 0.972 & $\mathrm{sp} 21=5$ & 0.835 & $\mathrm{sp} 37=8$ & 0.949 \\
\hline $\mathrm{sp} 14=4$ & 0.762 & $\mathrm{sp} 42=4$ & 0.975 & $\mathrm{sp} 23=4$ & 0.852 & $\mathrm{sp} 39=5$ & 0.958 \\
\hline $\mathrm{sp} 15=3$ & 0.776 & $\mathrm{sp} 43=5$ & 0.983 & $\mathrm{sp} 24=5$ & 0.856 & $\mathrm{sp} 41=5$ & 0.972 \\
\hline $\mathrm{sp} 16=1$ & 0.784 & $\mathrm{sp} 44=1$ & 0.988 & $\mathrm{sp} 25=3$ & 0.891 & $\mathrm{sp} 44=5$ & 0.988 \\
\hline
\end{tabular}

\section{A. Result}

The execution of the proposed calculation is investigated utilizing Sushisen algorithms look inquiry strategy by thinking about the accompanying three arrangement of bring to lights feature extraction (fig 3) A, $\mathrm{B}, \mathrm{C}$ bring to lights chosen to utilize A, B,C bring to lights ASD amygdala chosen by All removed 240 bring to lights.

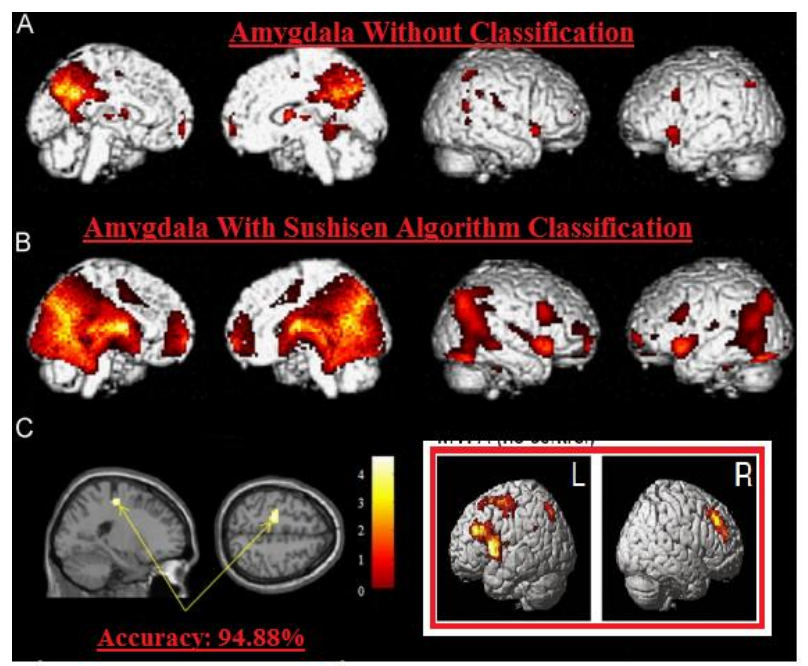

Fig 3: Results about Image ASD array longevity because the partial Amydala Accuracy stability fMRI
The amygdalae ("almond") is thought to have numerous critical parts, including dread molding, memory combination, and in the age of imperative passionate reactions image get analysis accuracy, which assist the cerebrum with processing recollections that are vital to image to accuracy improved in particular ASD. One plausibility is that there are constantly fewer neurons in the amygdala of individuals with extreme Diagnostic Interview for Social and Communication Disorders (CD). Another plausibility is that extreme Brain image storage sushisen $\operatorname{ASD}($ table.2) is a degenerative procedure happens sometime down the road and prompts neuron misfortune.

Table 2: Formation about ASD Matrix for $0^{\circ}, 90,125,155$ Direction Amygdala Between fMRI Pixels Sorting the scale into rising system and fMRI the score

\begin{tabular}{|l|l|l|l|l|}
\hline Classifier & Tumor Type & $\begin{array}{l}\text { Number of Test } \\
\text { Images }\end{array}$ & $\begin{array}{l}\text { Correctly Classified } \\
\text { Images }\end{array}$ & Classification rate (\%) \\
\hline \multirow{3}{*}{ Sushisen ASD } & fMRI With CNN & 120 & 113 & 94.83 \\
\cline { 2 - 6 } & fMRI with out CNN & 120 & 105 & 92.22 \\
\hline \multirow{3}{*}{$\begin{array}{l}\text { Sushisen } \\
\text { ASD }\end{array}$} & MRI with CNN & 120 & 102 & 85 \\
\cline { 2 - 6 } & MRI with out CNN & 120 & 98 & 81.67 \\
\hline
\end{tabular}




\begin{tabular}{|l|l|l|l|l|}
\hline \multirow{2}{*}{$\begin{array}{l}\text { Sushisen } \\
\text { ASD }\end{array}$} & CT with CNN & 120 & 99 & 82.5 \\
\cline { 2 - 5 } & CT With CNN & 120 & 94 & 78.33 \\
\hline
\end{tabular}

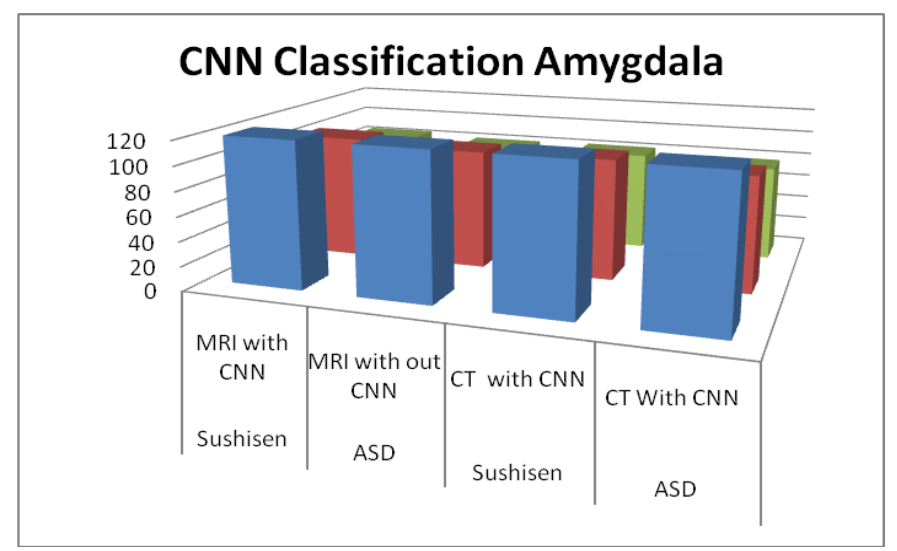

\section{B. Comparatives and study}

The cross validation accuracies nearby way of DCM then sparse logistic regression strategies are Accuracy 67\%. For mangy GST(General Systems Theory) on $77 \%$ and $66 \%-88 \%$, all the classification methods begotten in DCM below chance levels. For Susen algorithm regarding $94.88 \%$ both DCM and ASA begotten in CNN above gamble degree Accuracy (Table:3).

Table 3: Comparison of FMRI using Amydala DCM with Sushisen

\begin{tabular}{|l|l|l|}
\hline Methods & Author & Accuracy \\
\hline The original DCM paper & Friston et al. 2003, NeuroImage & $67 \%$ \\
\hline Role of General Systems Theory & Stephan 2004, J Anatomy & $77 \%$ \\
\hline $\begin{array}{l}\text { DCM: Ten simple rules for the } \\
\text { clinician }\end{array}$ & Kahan et al. 2013, NeuroImage & $66 \%$ \\
\hline Ten Simple Rules for DCM & Stephan et al. 2010, NeuroImage & $79 \%$ \\
\hline Two-state DCM & Marreiros et al. 2008, NeuroImage & $83 \%$ \\
\hline Non-linear DCM & Stephan et al. 2008, NeuroImage & $85 \%$ \\
\hline Stochastic DCM & $\begin{array}{l}\text { Li et al. 2011, NeuroImage } \\
\text { Friston et al. 2011, NeuroImage } \\
\text { Daunizeau et al. 2012, Front Comput } \\
\text { Neurosci }\end{array}$ & $87 \%$ \\
\hline A DCM for Resting State fMRI & Friston et al., 2014, NeuroImage & $88 \%$ \\
\hline $\begin{array}{l}\text { DCM With Sushisen } \\
\text { ASA }\end{array}$ & \begin{tabular}{l} 
Lalitha \& Jebamalar \\
\hline
\end{tabular} & $94.88 \%$ \\
\hline
\end{tabular}

\section{CONCLUSION}

The human genome grouping was an extraordinary accomplishment, and awesome advancement as far as sicknesses investigation was normal. We pointed in this work to take an interest in the comprehension of complex diseases. The objective was to manufacture a structure ready to investigate the Amygdala information and recognize sound and influenced tests. In this work we proposed a cross-breed bring to light choice model to choose the ideal subset of ASD From these outcomes we infer that ASD of the entire genome can be effectively utilized to recognize influenced people with complex sicknesses from the solid ones. Different vital surface bring to lights of fMRI check cerebrum pictures have been removed by utilizing dark level coevent grids. A new channel based administered calculation for include choice called sushisen algorithms is

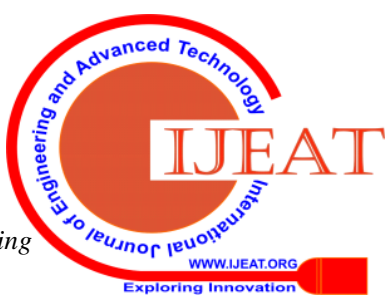


proposed and very much clarified. The pertinence of the chose bring to lights are contrasted and another arrangement of bring to lights chosen by customary calculation called Help by utilizing inquiry image mining technique. The test $\mathrm{R}$ Language results Amygdalae brain real data set have demonstrated that bring to light analysis chosen by the proposed technique produces higher arrangement rate. Feature Extraction and assess a product design acknowledgment framework to enhance order exactness among essential and metastatic mind tumors on X-ray. The framework enhanced arrangement exactness contrasted with different investigations. In this manner the framework could be of help to doctor as a dependable second supposition instrument while breaking down cerebrum tumor and ASD fMRI image accuracy Results.

\section{REFERENCES}

1. Chakrabarti S, Fombonne E.Pervasive developmental disorders in preschool children: confirmation of high prevalence. Am J Psychiatry. 2005 Jun;162(6):1133-41.

2. Ozonoff, S., Rogers, S. J., \& Hendren, R. L. (Eds.). (2003). Autism spectrum disorders: A research review for practitioners. Arlington, VA, US: American Psychiatric Publishing,

3. Mahjouri S, Lord CE. What the DSM-5 portends for research, diagnosis, and treatment of autism spectrum disorders. Curr Psychiatry Rep 2012; 14:739-747

4. Halfon N, Kuo AA. What DSM-5 could mean to children with autism and their families. JAMA Pediatr 2013; 167(7):608-613

5. Huerta M, Bishop SL, Duncan A, Hus V, Lord C. Application of DSM-5 criteria for autism spectrum disorder to three samples of children with DSM-IV diagnoses of pervasive developmental disorders. Am J Psychiatry 2012; 169:1056-1064

6. Tabtah, F. (2017). Autism Spectrum Disorder Screening: Machine Learning Adaptation and DSM-5 Fulfillment. Proceedings of the 1st International Conference on Medical and Health Informatics 2017, pp.1-6. Taichung City, Taiwan, ACM.

7. Anne B Arnett, Sandy Trinh, Raphael A Bernier,The state of research on the genetics of autism spectrum disorder: methodological, clinical and conceptual progress,Current Opinion in Psychology,Volume 27,2019,Pages 1-5.

8. Chantell Balaan, Michael J. Corley, Tiffany Eulalio, Ka'ahukane Leite-ahyo, Alina P.S. Pang, Rui Fang, Vedbar S. Khadka, Alika K. Maunakea, Monika A. Ward,Juvenile Shank3b deficient mice present with behavioral phenotype relevant to autism spectrum disorder,Behavioural Brain Research,Volume 356,2019,Pages 137-147.

9. Yao Wang, Yunhua Xiao, Yun Li, Kangkang Chu, Min Feng, Chunyan Li, Nana Qiu, Jiao Weng, Xiaoyan Ke,Exploring the relationship between fairness and 'brain types' in children with high-functioning autism spectrum disorder,Progress in Neuro-Psychopharmacology and Biological Psychiatry,Volume 88,2019,Pages 151-158,

10. A. Girardi, S.D. Sala, S.E. Macpherson,Theory of mind and the ultimatum game in healthy adult aging Exp. Aging Res., 44 (3) (2018), pp. 246-256.

11. X. Gong, L.X. Xia, Y. Sun, L. Guo, V.C. Carpenter, Y. Fang, Y. Chen,Proposal allocation ratio as a moderator of interpersonal responsibility effects on hostile decision-making in the ultimatum game Front. Psychol., 8 (1959) (2017), pp. 1-10, 10.3389/fpsyg.2017.01959

12. D. Ikuse, M. Tani, T. Itahashi, H. Yamada, H. Ohta, T. Morita, A Iwanami The effect of visual cues on performance in the ultimatum game in individuals with autism spectrum disorder Psychiatry Res., 259 (1) (2017), pp. 176-183, 10.1016/j.psychres.2017.10.013

13. L.B. Jahromi, C.I. Bryce, J. Swanson, The importance of self-regulation for the school and peer engagement of children with high-functioning autism Res. Autism Spectr. Disord., 7 (2) (2013), pp. 235-246, 10.1016/j.rasd.2012.08.012

14. Y. Su, T. Ma Fair decision making in children with autism spectrum disorder: theory-of -mind and self-other emotional recognition . Psychol. Sci., 37 (4) (2014), pp. 985-992

15. Seibert TM, Karunamuni R, Bartsch H, et al. Radiation dose-dependent hippocampal atrophy detected with longitudinal volumetric magnetic resonance imaging. Int J Radiat Oncol Biol Phys 2017;97:263-9. https://doi. org/10.1016/j.ijrobp.2016.10.035.

16. Karunamuni R, Bartsch H, White NS, et al. Dose-dependent cortical thinning after partial brain irradiation in high-grade glioma. Int J Radiat Oncol Biol Phy 2016;94:297-304. https://doi.org/10.1016/j.ijrobp.2015.10.026.

17. Vrtička, P., Sander, D., \& Vuilleumier, P. (2011). Effects of emotion regulation strategy onbrain responses to the valence and social content of visual scenes. Neuropsychologia,49(5), 1067-1082. https://doi.org/10.1016/j.neuropsychologia.2011.02.020.

18. Bamford, S., Broyd, S. J., Benikos, N., Ward, R., Wiersema, J. R., \& Sonuga-Barke, E. (2015). The late positive potential: A neural marker of the regulation of emotionbased approach-avoidance actions? Biological Psychology, 105, 115-123. https://doi org/10.1016/j.biopsycho.2015.01.009.

19. Nuss, P. Anxiety disorders and GABA neurotransmission: a disturbance of modulation. Neuropsychiatr. Dis. Treat. 11, 165-175 (2015).

20. Caro Lucas, Danial Shahmirzadi \& Nima Sheikholeslami (2004) Introducing Belbic: Brain Emotional Learning Based Intelligent Controller, Intelligent Automation \& Soft Computing, 10:1, 11-21, DOI: 10.1080/10798587.2004.10642862

21. C. Allison, B. Auyeung, S. Baron-Cohen (2012) Toward Brief "Red Flags" for Autism Screening: The Short Autism Spectrum Quotient and the Short Quantitative Checklist in 1,000 Cases and 3,000 Controls Journal of the American Acad of Child \& Adolescent Psychiatry

22. Alvaro Vargas-Clara, Sangram Redkar. (2015) Unmanned Ground Vehicle Navigation Using Brain Emotional Learning Based Intelligent Controller (BELBIC). Smart Science 3:1, pages 10-15.

23. Friston, K.J., Harrison, L., Penny, W., 2003. Dynamic causal modelling. Neuroimage 19,1273-1302.

24. N. Khalili, N. Lessmann, E. Turk, N. Claessens, R. de Heus, T. Kolk, M.A. Viergever, M.J.N.L. Benders, I. Išgum,Automatic brain tissue segmentation in fetal MRI using convolutional neural networks, Magnetic Resonance Imaging,2019, https://doi.org/10.1016/j.mri.2019.05.020.

25. Cao, F., Bitan, T., Booth, J.R., 2008. Effective brain connectivity in children with reading difficulties during phonological processing. Brain. Lang

26. Gross, J. J. (1998). Antecedent-and response-focused emotion regulation: Divergent consequences for experience, expression, and physiology. Journal of Personality and

27. Social Psychology, 74(1), 224.

28. Gross, J. J., \& Levenson, R. W. (1993). Emotional suppression: Physiology, self-report,and expressive behavior. Journal of Personality and Social Psychology, 64(6), 970-986.

29. https://doi.org/10.1037/0022-3514.64.6.970. 